\title{
Artificial ventilation for neurological disease: retrospective analysis $1972-81$
}

\author{
J G DOUGLAS，R J FERGUSSON, G K CROMPTON, I W B GRANT
}

\begin{abstract}
During the 10 year period $1972-81,39$ patients with neurological disorders referred to a respiratory unit required artificial ventilation, seven on two occasions. The decision to undertake ventilation was usually made on clinical grounds because of deteriorating respiratory effort, ineffective cough, or inability to swallow. Arterial blood gas studies were of limited value in assessing the need for ventilation.

The most frequent complication was bronchopulmonary infection which occurred in almost every patient, Staphylococcus pyogenes, Pseudomonas pyocyanea, and coliforms being the organisms most commonly isolated. In contrast, serious complications of tracheostomy and pulmonary thromboembolism occurred infrequently. There were 10 deaths among the 39 patients ventilated on 46 occasions; six were directly attributable to the neurological disease itself but four resulted from complications of artificial ventilation.
\end{abstract}

\section{Introduction}

Respiratory failure is a frequent cause of death in many neurological diseases. Failure of brain stem function may reduce respiratory drive, and failure of muscles innervated by brain

\footnotetext{
Respiratory Medicine Service, Northern General Hospital, Edinburgh EH5 2DQ

J G DOUGLAS, MRCP, senior registrar

R J FERGUSSON, MRCP, registrar

G K CROMPTON, FRCPED, consultant physician

I W B GRANT, FRCPED, consultant physician

Correspondence to: Dr J G Douglas.
}

stem nuclei can cause difficulties in breathing, coughing, and swallcwing. The latter may lead to retention of bronchial secretions and inhalation of saliva and food with subsequent lobar or segmental collapse and pneumonia. Paralysis of intercostal and diaphragmatic muscles results in underinflation of the lungs and may also reduce pulmonary compliance because of the development of diffuse microatelectasis. ${ }^{1}$ Artificial ventilation, although not indicated when respiratory failure is a terminal event in a chronic illness, may be critically important in the survival of patients with diseases such as myasthenia gravis or the Guillain-Barré syndrome in whom recovery can be expected. Early recognition of failing respiration in these patients followed by immediate transfer to a respiratory intensive care unit is then essential.

During the past few years there have been many technical advances in the management of patients requiring mechanical ventilation, and prolonged ventilatory support over many months is now practicable. ${ }^{2}$ Many major problems, however, still exist, particularly the risk of infection and the local trauma of prolonged intubation.

The purpose of this retrospective survey was to examine the indications for artificial ventilation, management, and outcome in patients with neurological disease admitted to this unit over the 10 year period $1972-81$.

\section{Patients and methods}

The case notes of all patients with neurological disease requiring artificial ventilation and admitted between 1972 and 1981 to the respiratory unit at the Northern General Hospital, Edinburgh, were reviewed.

\section{ROUTINE MANAGEMENT}

All patients were ventilated by intermittent positive pressure using a Cape Ventilator Mk III (Cape Engineering Company Limited, The 
Cape, Warwick CV34 5DL). Tracheostomy was routinely performed when prolonged ventilation was expected. Before 1977 rubber high pressure cuffed endotracheal tubes were used, these being deflated for at least two minutes every two hours. A change was then made to Portex (Portex Limited, Hythe, Kent CT21 6JL) "softseal" tubes with low pressure high volume cuffs which were kept constantly inflated. Such tubes were replaced routinely on the third day and on alternate days thereafter in an attempt to reduce bacterial colonisation. Tracheobronchial suction using endobronchial catheters was performed hourly and a trap specimen of secretions sent for bacteriological culture each day. After the advent of fibreoptic instruments bronchoscopy was used to achieve more effective bronchial toilet. Postural drainage and chest percussion were performed twice daily, ventilation being maintained with an Ambu bag. Tracheostomy dressings were changed every eight hours. Daily passive movement of all limb joints was performed by physiotherapists and, except in the first few years, subcutaneous heparin ( 5000 units three times daily) was given as prophylaxis against venous thrombosis and pulmonary embolism. When necessary patients were fed by nasogastric tube, and during the last four years all received intravenous cimetidine as prophylaxis against gastroduodenal haemorrhage.

\section{Results}

During the 10 years covered by the survey, 39 patients $(18$ men and 21 women) required artificial ventilation for neurological disorders on 46 occasions (table I). Over two thirds of the patients had either polyneuropathy or myasthenia gravis. Four had multiple sclerosis and four had other disorders affecting the brain stem (three thought to be due to a viral infection and one with suspected pontine haemorrhage). Two had confirmed viral encephalitis (measles and herpes simplex) and the reasons for ventilation in the other two were cervical myelopathy and status epilepticus treated with continuous intravenous thiopentone infusion. Seven patients required ventilation twice, four with myasthenia gravis, two with polyneuropathy, and one with multiple sclerosis and brain stem involvement. The duration of ventilation varied considerably, extending to over seven months in a man with severe brain stem encephalitis.

\section{ASSESSMENT BEFORE VENTILATION}

In most cases the decision to undertake artificial ventilation was based on a clinical impression of diminishing capacity for respiratory effort and inability to cough or swallow effectively. On 10 occasions ventilation was performed as an emergency after respiratory arrest; five of these patients had myasthenia gravis.

Arterial blood gas studies were carried out on 30 occasions immediately before ventilation (table II). These measurements did not always correspond with clinical assessment. Twenty one patients had a $\mathrm{PaO}_{2}$ of less than $10 \mathrm{kPa}\left(<75 \mathrm{~mm} \mathrm{Hg}\right.$ ) and seven also had a $\mathrm{PaCO}_{2}$ of greater than $6.0 \mathrm{kPa}(>45 \mathrm{~mm} \mathrm{Hg})$. In nine patients, however, both were normal. The duration of ventilation required in these patients was shorter than in those with blood gas abnormalities.

\section{COMPLICATIONS OF VENTILATION}

Cardiac arrhythmias during induction of general anaesthesia

Serious ventricular arrhythmias occurred in five patients during the induction of general anaesthesia for tracheal intubation or tracheostomy. Four had progressive polyneuropathy and the other myasthenia
TABLE II-Arterial blood gas measurements immediately before ventilation

\begin{tabular}{|c|c|c|}
\hline Partial arterial pressures $(\mathrm{kPa})$ & $\begin{array}{c}\text { No of } \\
\text { patients }\end{array}$ & $\begin{array}{l}\text { Mean duration of } \\
\text { ventilation (days) }\end{array}$ \\
\hline \multirow{3}{*}{$\left.\begin{array}{l}\text { Oxygen >10 } \\
\text { Carbon dioxide }<6 \\
\text { Oxygen }<10 \\
\text { Carbon dioxide }<6 \\
\text { Oxygen }<10 \\
\text { Carbon dioxide }>6\end{array}\right\}$} & 9 & 10 \\
\hline & 14 & 37 \\
\hline & 7 & 36 \\
\hline
\end{tabular}

gravis. The patients with polyneuropathy had been given suxamethonium as a muscle relaxant. All five patients survived these episodes.

\section{Infection}

Lower respiratory tract infections were common. Bacteriological cultures of specimens obtained by tracheal suction yielded pathogens during 45 of the 46 ventilations; bacteriological reports were not available on the last occasion. On $18(40 \%)$ occasions Staphylococcus pyogenes was isolated; 13 isolates were shown to be penicillinaseproducing organisms. On $14(31 \%)$ occasions Pseudomonas pyocyanea and on $13(29 \%)$ coliforms were reported. Other pathogens were less common: Haemophilus influenzae on 10 occasions, Streptococcus pneumoniae on eight, Streptococcus viridans on two, and Klebsiella aeruginosa on one. One patient was found to have active tuberculosis.

Radiographic changes of pulmonary consolidation or lobar collapse, or both, were observed during ventilation on 23 occasions $(50 \%)$. Despite the introduction of fibreoptic bronchoscopy the incidence of these bronchopulmonary complications remained unchanged throughout the 10 years of the study.

\section{Complications of tracheostomy}

Tracheostomy was performed during 21 ventilations. Problems with the management of the tracheostomy were encountered in six patients. Two patients had recurrent cellulitis around the tracheostomy stoma and one subsequently developed a persistent fistula after extubation which required surgical closure. In two patients ventilated for eight and 23 days the tracheostomy stoma stenosed and had to be refashioned. Recurrent haemorrhage from the tracheostomy occurred in one patient. Tracheal dilatation was recognised in only one patient after 160 days of ventilation using a Portex "soft-seal" low pressure high volume cuffed tracheostomy tube. This gradually worsened and after 237 days fatal haemorrhage occurred. Necropsy showed that the tracheostomy cuff had eroded into the brachiocephalic artery. None of the survivors developed stridor or other evidence of tracheal stenosis.

\section{Pulmonary thromboembolism}

Overt pulmonary embolism occurred in three patients, all of whom had polyneuropathy. None of these patients died. Necropsies were performed on seven of the 10 patients who died and in none was evidence found of deep venous thrombosis or pulmonary embolism.

\section{Renal failure and hyponatraemia}

Acute renal failure with blood urea rising to over $17 \mathrm{mmol} / \mathrm{l}$ $(100 \mathrm{mg} / 100 \mathrm{ml})$ developed during four ventilations. In three cases

TABLE I-Details of the 39 patients ventilated on 46 occasions for neurological disorders (1972-81)

\begin{tabular}{|c|c|c|c|c|c|c|c|}
\hline \multirow[b]{2}{*}{ Neurological disorder } & \multirow{2}{*}{$\begin{array}{c}\text { No of } \\
\text { ventilations } \\
\text { (patients) }\end{array}$} & \multicolumn{2}{|c|}{ Age (years) } & \multicolumn{2}{|c|}{$\begin{array}{l}\text { Interval between onset of } \\
\text { symptoms and ventilation (days) }\end{array}$} & \multicolumn{2}{|c|}{ Duration of ventilation (days) } \\
\hline & & Mean & Range & Mean & Range & Mean & Range \\
\hline $\begin{array}{l}\text { Polyneuropathy } \\
\text { Myasthenia gravis } \\
\text { Multiple sclerosis with brain stem involvement } \\
\text { Other disorders affecting brain stem } \\
\text { Viral encephalitis } \\
\text { Cervical myelopathy } \\
\text { Status epilepticus }\end{array}$ & $\begin{array}{l}19(17) \\
14(10) \\
5(4) \\
4(4) \\
2(2) \\
1(1) \\
1(1)\end{array}$ & $\begin{array}{l}47 \cdot 9 \\
51 \cdot 4 \\
38 \cdot 8 \\
49 \cdot 5 \\
44 \\
42 \\
42\end{array}$ & $\begin{array}{l}18-75 \\
13-75 \\
28-52 \\
41-60 \\
38-50\end{array}$ & $\begin{array}{l}43 \cdot 9 \\
25 \cdot 4 \\
15 \cdot 3 \\
12 \cdot 3 \\
12 \\
3 \\
0 \cdot 5\end{array}$ & $\begin{array}{c}2-182 \\
2 h-54 \\
3-28 \\
1-41 \\
5-19\end{array}$ & $\begin{array}{c}24 \cdot 2 \\
12 \cdot 1 \\
9 \\
67 \cdot 1 \\
9 \cdot 5 \\
4 \\
20\end{array}$ & $\begin{array}{c}1-155 \\
4-21 \\
2-12 \\
0 \cdot 5-237 \\
2-17\end{array}$ \\
\hline
\end{tabular}


this was associated with pneumonia and septicaemia, and in the remaining case it was thought to be the result of severe hypoxia before ventilation. Two of these patients subsequently died, one despite peritoneal dialysis.

During six other ventilations (four in patients with polyneuropathy) the plasma sodium concentration fell to below $130 \mathrm{mmol} / 1$. Plasma osmolality, measured in five patients, was below $275 \mathrm{mmol} / \mathrm{kg}$, indicating a dilutional hyponatraemia, and in four patients urine osmolality was over $720 \mathrm{mmol} / \mathrm{kg}$, suggesting inappropriate secretion of antidiuretic hormone. In every instance the hyponatraemia was successfully treated by either water restriction or the use of hypertonic saline, but three of these patients subsequently died from other causes.

\section{Other complications}

Serious gastroduodenal haemorrhage requiring blood transfusion did not occur and no patient developed pressure sores.

\section{OUTCOME OF TREATMENT}

There was a fatal outcome in 10 cases (table III). Three of these deaths were attributable to the neurological disorder itself and in a further three artificial ventilation was stopped because of evidence of irreversible cerebral damage sustained during a cardiorespiratory arrest before ventilation. Four deaths were related to direct or indirect complications of ventilation: erosion of the brachiocephalic artery by the tracheostomy cuff in one and septicaemia in the other three (caused by Staph pyogenes in two and Ps pyocyanea in one). Both patients with staphylococcal septicaemia died from renal failure.

TABLE III-Individual details of the 10 deaths during ventilation

\begin{tabular}{|c|c|c|c|}
\hline Neurological disorder & $\begin{array}{l}\text { Patient's } \\
\text { age (years) }\end{array}$ & $\begin{array}{l}\text { Interval } \\
\text { between } \\
\text { onset of } \\
\text { symptoms and } \\
\text { ventilation } \\
\text { (days) }\end{array}$ & $\begin{array}{c}\text { Duration of } \\
\text { ventilation } \\
\text { (days) }\end{array}$ \\
\hline Polyneuropathy & 75 & 160 & 70 \\
\hline Myasthenia gravis & $\begin{array}{l}42 \\
69\end{array}$ & $\begin{array}{r}46 \\
1\end{array}$ & $\begin{array}{l}1 \\
5\end{array}$ \\
\hline Multiple sclerosis with brain stem & 67 & 5 & 4 \\
\hline involvement & $\begin{array}{l}52 \\
43\end{array}$ & $\begin{array}{l}3 \\
2\end{array}$ & $\begin{array}{l}2 \\
3\end{array}$ \\
\hline Other disorders affecting brain stem & 52 & 40 & 237 \\
\hline & 60 & 1 & $0 \cdot 5$ \\
\hline Viral encephalitis & $\begin{array}{l}38 \\
50\end{array}$ & $\begin{array}{r}5 \\
19\end{array}$ & $\begin{array}{r}2 \\
17\end{array}$ \\
\hline
\end{tabular}

\section{Polyneuropathy}

Two of the $17(12 \%)$ patients with polyneuropathy died. One was the patient who developed pseudomonal septicaemia secondary to pneumonia. In the other, artificial ventilation was stopped because of evidence of irreversible brain damage sustained during a cardiorespiratory arrest before ventilation. Ventilation was followed by complete neuromuscular recovery at the time of discharge from hospital in eight of the $15(53 \%)$ survivors and by partial recovery in seven $(47 \%)$.

\section{Myasthenia gravis}

Two of the 10 patients with myasthenia gravis died. These included one of the two patients who died from staphylococcal septicaemia and acute renal failure. The other had symptoms of acute myasthenia gravis for five days before ventilation and died four days later. Necropsy showed no cause other than myasthenia gravis for this patient's death. Eight of the 14 episodes of ventilation for this condition were followed by complete neurological recovery $(57 \%)$ and four by partial recovery $(29 \%)$.

\section{Other conditions}

Two of the four patients with multiple sclerosis died, both within four days. One was the second of the two patients who died from staphylococcal septicaemia and acute renal failure. The other sustained irreversible brain damage during a cardiorespiratory arrest before ventilation. Two of the four patients with other brain stem disorders died during ventilation, one from erosion of the brachiocephalic artery by the tracheostomy cuff after 237 days, the other as a consequence of irreversible cerebral damage 12 hours after a cardiorespiratory arrest. The two patients with viral encephalitis had had respiratory arrests before ventilation and both subsequently died. Necropsy in each case showed evidence of fulminant disease with no other cause of death. One patient with cervical myelopathy was found to have active pulmonary tuberculosis during ventilation. After four days' chemotherapy respiratory function had improved and ventilation was stopped. The patient remained tetraplegic and died six weeks later at home. Overall, of the 13 episodes of ventilation in this miscellaneous group, six were followed by partial neuromuscular recovery, six patients died during ventilation, and only the one with status epilepticus made a complete recovery.

\section{Discussion}

Intermittent positive pressure ventilation is now standard treatment for patients with respiratory failure associated with reversible neurological disease and has been successfully maintained for as long as 30 months. ${ }^{2}$ Of 176 patients with acute Guillain-Barré syndrome seen over nine years in the New York metropolitan area, $41(23 \%)$ required tracheostomy and artificial ventilation. ${ }^{3}$ This treatment was also required in 31 (21\%) of 154 patients with myasthenia gravis attending Manchester Royal Infirmary between 1969 and $1978 .{ }^{4}$ There are, however, surprisingly few reports of the indications for artificial ventilation and of its results and complications.

Hypoxaemia with or without hypercapnia might be expected in patients with respiratory muscle weakness. Indeed, of the 30 measurements of arterial blood gas tensions performed immediately before ventilation in this series, 14 had type I respiratory failure and seven had type II respiratory failure. A surprising finding was, however, that nine patients had normal arterial blood gas tensions before ventilation. The probable explanation of this apparent paradox is that in many cases artificial ventilation was started for other reasons-such as respiratory distress, ineffective coughing, or inability to swallow-before the development of notable hypoxaemia or hypercapnia.

Life threatening ventricular arrhythmias during induction of anaesthesia in four of our patients with polyneuropathy have been reported. ${ }^{5}$ Suxamethonium, which was used in all these cases as a muscle relaxant, may induce hyperkalaemia and ventricular arrhythmias in patients with neurological disorders. ${ }^{6}$ Non-depolarising agents should, therefore, be used in all patients with neurological disease who require muscle relaxation during general anaesthesia.

Bronchopulmonary infection was a very common complication. The fibreoptic bronchoscope has greatly facilitated the removal of secretions from the bronchi but, in our experience, has failed to reduce the incidence of serious pulmonary infections, most of them caused by Staph pyogenes, Ps pyocyanea, and coliform organisms. There was, however, no clear correlation between the isolation of these organisms from tracheal aspirates and the development of pneumonic lesions. Only the patient who was ventilated for 237 days was a confirmed source of cross infection.

Skilled nursing care was probably the main reason for the low incidence of serious complications of tracheostomy. Nevertheless, prolonged ventilation using a cuffed tracheostomy tube is always hazardous and may cause tracheal dilatation and eventual erosion of the oesophagus or a major artery.

A review of 35 patients who died during ventilation for severe respiratory failure showed that, although only $3 \%$ were thought to have died from massive pulmonary embolism, $20 \%$ had evidence of pulmonary embolism at necropsy. ${ }^{7}$ In a similar study of 66 deaths during artificial ventilation $18(27 \%)$ were found to have pulmonary embolism at necropsy. ${ }^{8}$ In contrast, overt pulmonary embolism was uncommon in our patients and in none of the seven necropsies was evidence of thromboembolic 
disease found. This may reflect the use of prophylactic subcutaneous heparin together with regular turning and passive limb movements.

The prognosis of patients who develop acute renal failure during ventilation is poor and in our study half of them died. Inappropriate secretion of antidiuretic hormone not infrequently occurs in various brain disorders, such as encephalitis and the Guillain-Barré syndrome. ${ }^{9}$ This complication may have occurred in four (possibly six) of our cases, thus emphasising the importance of monitoring the plasma sodium concentration in all patients with neurological disorders-particularly those affecting the brain stem-who require artificial ventilation.

Twelve per cent of our patients ventilated for polyneuropathy died, which is slightly below the $19.5 \%$ reported in a series of 41 patients in New York. ${ }^{3}$ Ashworth and Hunter observed a 70\% death rate in patients with myasthenia gravis and ventilatory failure treated at Manchester Royal Infirmary between 1960 and 1969.10 A similar retrospective study in the following decade (1969-78) at the same hospital showed that the mortality had fallen to $36 \%$ compared with $20 \%$ for patients with myasthenia gravis in our own study. These reductions in death rate from myasthenia gravis and polyneuropathy may be related to earlier recognition of the indications for artificial ventilation. The death rate for patients with multiple sclerosis and other brain stem disorders, and with viral encephalitis, was inevitably much higher, and in such conditions artificial ventilation is usually seen in retrospect to have been a futile exercise.

Advances in the technology of artificial ventilation-combined with a better understanding of respiratory physiology, more effective antibacterial drugs, and greater expertise in medical and nursing care-have dramatically improved the prognosis of patients with some types of neurological disease whose respiratory and brain stem function are seriously compromised. The fact remains, however, that although in our survey there were only 10 deaths in 39 patients ventilated on 46 occasions, four of these deaths were due to complications of artificial ventilation. Although such complications are difficult to prevent and the scope for any further reduction in death rate from these causes is small, our experience has shown that well organised intensive care facilities and strict attention to the details of patient care by both doctors and nurses are essential to keep it to a minimum. Unfortunately, not all conventional respiratory intensive care units are geared to the needs of patients who require long term artificial ventilation, and the logistics of providing such facilities for both medical and surgical neurological units deserve much more attention than they have received in the past.

We thank Drs B Ashworth, E H Jellinek, and the late C Mawdsley, consultant neurologists, for allowing us to review patients under their care.

\section{References}

1 de Troyer A, Deisser P. The effects of intermittent positive-pressure breathing on patients with respiratory muscle weakness. Am Rev Respir Dis $1981 ; 124: 132-7$.

${ }^{2}$ Knoedler JP. Delayed recovery from respiratory paralysis due to the Guillain-Barré syndrome. Chest 1981 ;80:119-20.

${ }^{3}$ Dowling PC, Menonna JP, Cook SD. Guillain-Barré syndrome in Greater New York-New Jersey. FAM $A$ 1977;238:317-8.

- Ferguson IT, Murphy RP, Lascelles RG. Ventilatory failure in myasthenia gravis. $\mathcal{F}$ Neurol Neurosurg Psychiatry $1982 ; 45: 217-22$.

${ }^{5}$ Fergusson RJ, Wright DJ, Willey RF, Crompton GK, Grant IWB. Suxamethonium is dangerous in polyneuropathy. Br Med $\mathcal{f} 1981 ; \mathbf{2 8 2}$ : 298-9.

6 Cooperman LH. Succinylcholine-induced hyperkalaemia in neuromuscular disease. F $A M A$ 1970;213:1867-71.

7 Moser KM, le Moine JR, Nachturey FJ, Spragg RG. Deep venous thrombosis and pulmonary embolism: frequency in a respiratory intensive care unit. $\mathcal{f} A M A 1981 ; 246: 1422-4$.

8 Neuhaus A, Bentz RR, Weg JG. Pulmonary embolism in respiratory failure. Chest 1978;73:460-5.

9 Zerbe R, Stropes L, Robertson GL. Vasopressin function in the syndrome of inappropriate antidiuresis. Ann Rev Med 1980;31:315-7.

10 Ashworth B, Hunter AR. Respiratory failure in myasthenia gravis. Proc $R$ Soc Med 1971;64:19-20.

(Accepted 7 April 1983)
What substances are available to protect the skin from sunburn?

Modern sunbarrier creams can be very effective. The use of an appropriate preparation on exposed areas of the body may theoretically permit a 20 to 30 -fold increase in sunlight exposure before burning occurs, although in practice such efficacy is usually not achieved. Sunscreens enable such an increase in exposure because they contain a sun protection factor. The manufacturer's assessment of this factor is usually marked on over the counter preparations but should be considered only as a guide because of varying methods of sun protection factor estimation and the vagaries of customer usage. With careful use, however, protection approaching a factor of 20 can probably be expected in practice. Since under 20 times the radiation dose for sunburn is the most likely amount to be received during any day worldwide, ${ }^{1}$ such protection should always be effective. The chosen preparation must, however, be carefully applied to all exposed areas, and although some sunscreens have prolonged effectiveness after a single application (so-called high substantivity) reapplication every hour or so during exposure is advisable. Tanning of the skin will usually occur in susceptible subjects even with the use of these sunscreens, but probably not so quickly. Many sunscreens available in the United Kingdom have recently been tested for sun protection factor independently of the manufacturers, ${ }^{2}$ and some of those shown to be most effective are now available on the NHS for people suffering from light sensitive skin disorders such as vitiligo or the photodermatoses. The approved products were all found to have sun protection factor values of greater than 12 , and they include the cosmetically acceptable vanishing absorbent preparations.

Opaque reflectant sunscreens are occasionally used. Despite being cosmetically unsatisfactory and rather messy they can be effective, with sun protection factor values of about 20-30. They are not, however, necessarily better than the absorbent type, except that they possess a slightly broader ultraviolet absorption spectrum, which is useful in some photodermatoses. This last factor makes them less likely to allow tanning. Available preparations are the white zinc paste compound $\mathrm{BP}$ or the more cosmetically suitable brownish $25 \%$ titanium dioxide and $8 \%$ burnt sugar in aqueous cream. They must be regularly reapplied as with the absorbent preparations or they will gradually dry and flake off. The choice of preparation depends partly on personal taste and partly on the sun protection factor appropriate for the skin colouring and the expected exposure. Fair skinned people who burn easily should begin with a product of sun protection factor 12 or more, those who tan slowly about $8-12$, and those who tan easily about 4-8. As tanning develops the product may be used less often or one of lower sun protection factor used instead. Side effects from use of sunbarrier creams may occasionally occur, particularly with the commercial absorbent preparations. Problems include transient skin irritation immediately after application and less commonly contact or photocontact dermatitis.

Precautions are important only when the sunlight is intense enough to produce burning, and this depends on the geographical location and time of day when exposure occurs. Avoidance of direct sunlight is not always a sufficient precaution since up to about two thirds of the incident ultraviolet radiation can be transmitted indirectly from the blue sky. Excessive exposure is more likely in areas where white sand or snow can reflect large amounts of radiation. Swimming also increases the likelihood of sunburn because water washes off sunbarrier creams and encourages prolonged exposure because of its cooling effect. Thus the type of activity being undertaken while in the sunshine is important in determining the likelihood of adverse effects. In general burning is most likely when sunbathing at the seaside, ${ }^{1}$ occurring after about half an hour at midday in summer. Beside a swimming pool, burning may take twice as long, while during sightseeing and sailing in summer or skiing in winter it will take twice as long again.-J L M HAWK, consultant dermatologist, London.

Diffey BL, Larkö O, Swanbeck G. UV-B doses received during different outdoor activities and UV-B treatment of psoriasis. Br $\mathcal{F}$ Dermatol 1982;106:33-41. Hawk JLM, Challoner AVJ, Chaddock L. The efficacy of sunscreening agents protection factors and transmission spectra. Clin Exp Dermatol 1982;7:21-31. common clothing fabrics. Clin Fxp Dermatol $1981: 6: 577-82$. 